Arab World English Journal (AWEJ) Volume 12. Number2 June 2021

DOI: https://dx.doi.org/10.24093/awej/vol12no2.18

Pp.268-278

\title{
Teacher-Centered Approach Prevalence in Algerian Secondary-School EFL Classes: The Case of English Teachers and Learners in Mostaganem District
}

\author{
Meriem Baghoussi \\ Department of English \\ Faculty of Letters and Languages, \\ University of Abdelhamid Ibn Badis \\ Mostaganem, Algeria
}

Received: 3/19/2021 Accepted: 6/3/2021

Published:6/24/2021

\begin{abstract}
Before implementing the Competency-Based Approach (CBA) in 2003, the Algerian educational system was based on traditional teaching methods that focused mainly on acquiring the knowledge about language delivered by the teacher and the amount of information the learner could accumulate to pass the exams. Although CBA has shifted the teacher's role from a knowledge transmitter to a facilitator and the learner from a passive recipient to an active participant, the teacher-centered paradigm still prevails among secondary-school teachers. To shed light on that prevalence, the researcher attempts to explore the perceptions secondaryschool teachers hold about Teacher-Centred Approach (TCA) and the reasons behind its widespread use. Therefore, the present study investigates the causes of TCA prevalence in English as a Foreign Language (EFL) classes using a mixed-methods approach. To reach that aim, the researcher put forward the following hypothesis. Although teachers know the various teaching approaches, they have to adopt the teacher-centered method because of several constraints. To collect the necessary data to identify those constraints, thirty English teachers from some secondary schools in the district of Mostaganem received a questionnaire. The research results confirmed the hypothesis stated above. They revealed that teachers are wellinformed about the viability of various teaching approaches and methods; however, they keep adopting the teacher-centered approach. Such behavior is due to multiple constraints such as classrooms crowdedness, the traditional physical classroom environment, the baccalaureate (BAC) exam requirements, and the time restrictions due to the lengthy English programs.
\end{abstract}

Keywords: Algerian secondary-school EFL classes, competency-based approach (CBA), teachercentered approach prevalence, traditional teaching methods

Cite as: Baghoussi, M . (2021). Teacher-Centred Approach Prevalence in Algerian SecondarySchool EFL Classes: The Case of English Teachers and Learners in Mostaganem District. Arab World English Journal, 12 (2) 268-278. DOI: https://dx.doi.org/10.24093/awej/vol12no2.18 


\section{Introduction}

Educational systems reforms aim at updating learning goals and objectives to make them more consistent with the needs of $21^{\text {st }}$-Century individuals, society, and the world. The educational reforms Algeria has put in train since 2002 aim to help our students acquire the necessary skills and competencies to face $21^{\text {st }}$-century challenges. Since English is the most widely spoken language globally and a language extensively used in scientific and technological fields, the Ministry of National Education (MNE) has integrated it in middle and secondary school education, where learners spend seven years learning it. To highlight its importance, the English curriculum designers note that Algeria's English teaching aims to plunge learners into the modern world. It also allows them to interact with the world communities, share and exchange ideas in different fields, understand each other and live in peace.

Before 2003, the Algerian educational system was based on the following teaching approaches: the Aural-Oral Approach, Objective-Based Approach, and the communicative approach. To overcome the deficiencies in the previous approaches, the MNE opted to adopt the Competency-Based Approach (CBA) in 2003. This approach embeds the Learner-Centred Approach (LCA) principles, and it derives from the constructivist theories of learning. Those approaches "take students seriously as active participants in their own learning, fostering transferable skills such as problem-solving, critical thinking and reflective thinking" (Attard et al., 2010, p.5).

To highlight the effectiveness of the CBA, the MNE (2006) states that the competencybased program offers learning situations and situations of integration that put learners at the center of the learning process and involve them in knowledge self-appropriation, which is a characteristic related to LCA. Those learning situations encourage learners' initiative and foster their creativity. They also encourage them to use various learning strategies and reinvest their acquired knowledge in real-life situations to solve problems. Besides, the program designers have integrated the project work and the group work pedagogy within the teaching process to raise learners' sense of autonomy and responsibility. They have also urged teachers to use Information Communication Technologies (ICTs) in classrooms and encourage their learners to use those tools to prepare and present their projects. Besides, assessment has become less teacher-based, and learners can assess themselves (self-assessment) and assess their peers (peerassessment). In such an environment, the teacher's role shifts from the knowledge possessor and provider to a facilitator and guide who creates a learning atmosphere that generates autonomy and gives learners opportunities to work in groups, collaborate, experiment, and discuss.

Although the English curriculums and CBA encompass the learner-centered approach and learner autonomy principles, teachers are still resistant to change and keep using the traditional teacher-centered teaching styles. Their utmost aim is to cover all of the curriculums and make students memorize as much content as possible so that they will be able to regurgitate it in exams, especially the BAC exam. The present paper investigates teachers' degree of awareness on the advantages of the learner-centered teaching approaches and the causes behind the TCA prevalence in secondary-school EFL classes. Eventually, the investigation results could help raise teachers' awareness about the drawbacks of TCA overuse and prevalence. 


\section{Literature Review}

\subsection{Characteristics of TCA}

Over the last few decades, the education field has undergone a steady transition from teachercentered to student-centered approaches in delivering content and assessing. The teachercentered method is mainly associated with traditional approaches to language teaching and learning, where "the instructor directs how, what, and when students learn" (Dupin-Bryant, 2004, p.42). Such a context conveys two images. In the first one, teachers are standing up "[...]on their feet in the front of the room with eyes open, asking questions, making points, gesturing, writing key ideas on the board, encouraging, correcting, demonstrating, and so forth" (Schug, 2013, p.94); in the second one, students are submissively sitting in desks, listening attentively and taking notes. As for the content to be taught, the educational institutions decide on how it should be taught (methods/approaches) and assessed (standardized tests) and which resources should be used (textbooks). Therefore, teachers are required to put into practice their institutions' plans and recommendations.

To define the teacher-centered approach, scholars have provided many descriptions. Otukile-Mongwaketse (2018) asserts that "when education is teacher-centered, the teacher retains full control of the classroom and its activities" (p.12). Therefore, control is predominant, and "authority is transmitted hierarchically" (Dollard et al., 1996, p.3); besides, while "designing the class activities, teachers control every single learning experience" (Emaliana, 2017, p.60). Muganga and Ssenkusu (2019) define it as "an educational system based upon rote learning and memorization" (p.16). Most scholars affirm that teachers transmit the course content to be memorized to students through lectures, notes, or handouts provided by the teacher. Moreover, to assess their ability to reproduce the teacher-delivered material, teachers give the students summative assessments in a standardized test form. To motivate students, teachers rely primarily on extrinsic motivation. Kitiashvili (2020) states that "teacher-centered pedagogy is linked with top-down and hierarchal pedagogy" (p.553). According to her, teachers are like experts who transmit knowledge to novices. Additionally, they take that knowledge blindly from specific textbooks that are mainly grammar-based and which both the teachers and learners are constrained to use. Toh K. A. (1994) gives a detailed description of the teacher-centered methodology and environment:

- Teacher talk exceeds student talk during instruction;

- Instruction is mostly with the entire class;

- Textbooks guide what is being taught in class;

- Each episode within the lesson is determined by the teacher;

- Desks and chairs are usually arranged into neat rows facing the chalkboard;

- Students are not free to roam from their seats (p.13).

\subsection{TCA Foundations}

The way people learn has always been the primary concern of educational psychologists. They shared their different thoughts on how people learn. The researches in this field have given birth to many pedagogical approaches. The main ones are behaviorism, constructivism, and social constructivism. The TCA has its roots in behaviorism. At the beginning of the 20th century, behaviorism took a predominant role in psychology. Behaviorists focus on the changes occurring in behavior due to stimuli (learning), but they ignore the internal thought processes as 
elements of actions. They also stipulate that what human beings learn is due to their interaction with the physical environment in which they live. Their theories minimize the influence of the innate or inherited factors on behavior; therefore, they focus not only on objectively observable behaviors but also on quantifiable and observable events. They believe that any reliable scientific research should rely on visible indicators and that the mind's independent activities are not to be considered. That belief has given another dimension to psychology, allowing psychologists to undertake multiple measurement types to understand some behaviors. Three notable behaviorists who made their names over the years are Pavlov, Watson, and Skinner.

\subsubsection{Pavlov's Classical Conditioning Theory}

Ivan P. Pavlov (1849-1936), a doctor and physiologist, was the first researcher who introduced the conditioning concept. His famous experiments on dogs have helped us understand behaviorism that is based on the stimulus-response paradigm. The scientific results Pavlov obtained influenced Watson and helped him justify the validity of his beliefs. In those experiments with a dog, Pavlov found out that the dog started to salivate each time he showed it food. Consequently, he concluded that salivation is a natural and innate process, and the unconditioned response is due to an unconditioned stimulus. To go further in his experiment, Pavlov then used a bell as an 'artificial' stimulus. Each time he wanted to feed the dogs, he rang a bell. After doing that for a certain period, the dog started to salivate when hearing the bell, even if the food was not available. That reaction is called a conditioned response. This kind of learning is also called Learning by Conditioning. Pavlov's work on classical conditioning has contributed significantly to the development of the behaviorism school of psychology.

Classical conditioning allows teachers to use it in various ways in the classroom. In such an environment, students are considered empty vessels, and in this case, teachers will mold them according to the desired profile by exposing them to specific stimuli. For example, students' unconditioned behaviors, such as working alone or keeping silent, can be conditioned and changed into collaborative and participative behaviors. Therefore, teachers could use classical conditioning to install excellent and favorable behaviors in the classroom.

Although Pavlov's theory had a tremendously positive influence on psychology, it has faced much criticism. The following are the most widespread ones:

- The theory is deterministic and does not allow for individuals' free will;

- It underestimates the uniqueness of human beings;

- Numerous environment variables can impact a person's reaction;

- Conditioned behaviors disappear if the expected outcome is no longer available.

\subsubsection{Watson's Learning Theory}

John B. Watson (1878-1958), the founder of the behaviorist theory, disagreed with the idea that heredity determined how a person behaved; he believed that people's overall learning experiences were the elements that determined how they reacted in various situations. Through the experiments Watson performed, he showed that he could condition or train a child to respond the way he wanted him to do. In this context, he said: 
Give me a dozen healthy infants, well-formed, and my own specified world to bring them up in and I'll guarantee to take any one at random and train him to become any type of specialist I might select - doctor, lawyer, artist, merchant-chief and, yes, even beggar-man and thief, regardless of his talents, penchants, tendencies, abilities, vocations and the race of his ancestors (Watson, 1924, p.104).

\subsubsection{Skinner's Operant Conditioning Theory}

Contrary to Pavlov and Watson's theories, Skinner (1938) believed that behavior is not influenced by the action that comes before it but rather by the causes and consequences of a particular action. That is what he called operant conditioning. This model outlines four methods of conditioning that could modify behavior. Ackerman (2020) summarized those methods as follows:

1. Positive reinforcement: a desirable stimulus is introduced to encourage certain behavior.

2. Positive punishment: an undesirable stimulus is introduced to discourage the behavior.

3. Negative reinforcement: an undesirable stimulus is removed to encourage the behaviour.

4. Negative punishment (also called extinction): a desirable stimulus is removed to discourage the behaviour (para. 2).

According to this approach, behavior that is followed by positive reinforcement, i.e., what a subject likes, is likely to happen again. However, if it is followed by negative reinforcement, i.e., what a subject hates, it is less likely to be repeated another time. In this case, "extension is the discontinuation of behaviors that had been encouraged by either negative or positive reinforcement" (Speaks, 2019). Therefore, the key elements of operant conditioning are reinforcement, punishment, and extension.

\subsection{Behaviorism Limitations}

The core element in the theories mentioned above is the teacher; therefore, her/his presence in the learning environment is crucial and necessary. That necessity transforms the classroom into a teacher-centered one where the teacher transfers information to students primarily through lecturing and strategies that place students' behavior under stimulus control (Brophy, 1999). While adopting such an approach, teachers spend most of the time explaining to students how they should respond to the target stimuli. During the learning process, where the teacher imposes authority, students are silent, attentive, and passively listening to the teacher's everlasting talks. The teacher uses those repetitive explanations on purpose. They give an idea to the students about the desired behavior to adopt or the information the teacher wants them to acquire and regurgitate in exams. With the emergence of constructivism in the mid-1990s, the behavioral approach faced some controversies. Ballard (1987) states that "a review of theory and research suggests, however, that the behavioral task analysis, the stimulus-response approach is not an appropriate nor effective model for interactive teaching" (p.197). Consequently, experiential, autonomous, collaborative, creative, technology-based, and problem-solving learning does not take place in such an environment since the teacher holds complete control on learners' learning process and "assumes primary responsibility for the communication of knowledge to students" (Mascolo, 2009, p.4). In the same context, Ballard (1987) adds that "behavioural methods present problems because they emphasize the control of learning by the instructor, thus devaluing pupil initiation..." (p.197). 


\section{Methodology}

\subsection{Method}

To investigate the prevalence of the teacher-centered approach in secondary-school English classes, the researcher adopted a mixed methods research. The researcher used a questionnaire directed to thirty secondary-school English teachers to collect the required information.

\subsection{Participants}

The informants were all active secondary-school English teachers in the district of Mostaganem, Algeria. The majority (95\%) of the informants who participated in the survey were females, but only a few (05\%) were males. The informants' age ranged between 24 and 48, and their teaching experience varied between two and twenty-five years.

\subsection{Research Tool}

The questionnaire handed to teachers contains five closed-ended, sixteen open-ended questions, and eleven sub-questions. It is composed of three main parts. The first part investigates the physical classroom environments and their populations; the second one explores the teachers' background knowledge on teaching approaches and the extent to which they put into practice those approaches. The last part examines the current teachers' teaching methodology and practices applied in classrooms by teachers.

\section{Findings, Discussion, and Analysis}

\subsection{Population and Classrooms Environment}

The data revealed that most participants $(80 \%)$ worked in rural secondary schools in the first part of the questionnaire. The majority $(70 \%)$ had crowded classes of more than thirty students per class; whereas, $30 \%$ of them had between twenty to thirty students in their classrooms. Such crowdedness engendered many problems and influenced teachers' practice. The following table gives more details about the drawbacks of over-crowdedness on teachers and students.

Table 1. The Drawbacks of Over-Crowdedness on Teachers and Students

\begin{tabular}{|l|c|}
\hline \multicolumn{1}{|c|}{ Over-Crowdedness Drawbacks } & Teachers' Choices \\
\hline A lot of stress/fatigue & $\mathbf{7 0 \%}$ \\
\hline Impossibility to use active learning strategies: group work, role-plays... & $\mathbf{6 7 \%}$ \\
\hline Lack of focus and concentration among students & $\mathbf{6 3 \%}$ \\
\hline Lack of individual attention to every student & $\mathbf{5 7 \%}$ \\
\hline Time-consuming/wasting & $\mathbf{4 7 \%}$ \\
\hline Assessment difficulties & $\mathbf{4 7 \%}$ \\
\hline Bad students' results & $\mathbf{4 3 \%}$ \\
\hline Problems of discipline/control & $\mathbf{4 0 \%}$ \\
\hline Classroom management difficulty & $\mathbf{3 3 \%}$ \\
\hline Impossibility to finish lessons/program & $\mathbf{3 3 \%}$ \\
\hline Reduction of participation/engagement & $\mathbf{3 0 \%}$ \\
\hline Much noise & $\mathbf{3 0 \%}$ \\
\hline Reduction of homework & $\mathbf{2 7 \%}$ \\
\hline None & $\mathbf{0 0}$ \\
\hline
\end{tabular}

When asked about the difficulties they encounter in overcrowded classrooms, the highest percentages referred to the amount of stress and fatigue those classrooms engender and the difficulties teachers find in using active learning strategies like group work, role-plays, and 
games. The other hindrances cited by teachers were the lack of focus and concentration among students, lack of individual attention to every student, the impossibility to finish the program due to time shortage, assessment difficulties, bad students' results, discipline and control problems, and other problems that Table 1 displays.

Because of classroom crowdedness, almost all the Algerian schools adopt the traditional seating arrangement - aligned rows facing the board. Almost all schools in Algeria adopt such a design. However, teachers can change it according to their needs during their practice before they start their lessons. In this context, most of the respondents (80\%) stated that they kept using the traditional model, but the minority noted that they adopted other class layout options: roundtable and semicircle.

\subsection{Teachers' Background Knowledge on Teaching Approaches}

The responses in the second part of the questionnaire stipulate that almost all the respondents (97\%) are knowledgeable about the teaching approaches that foster teacher-centredness and hinder learner-centredness.

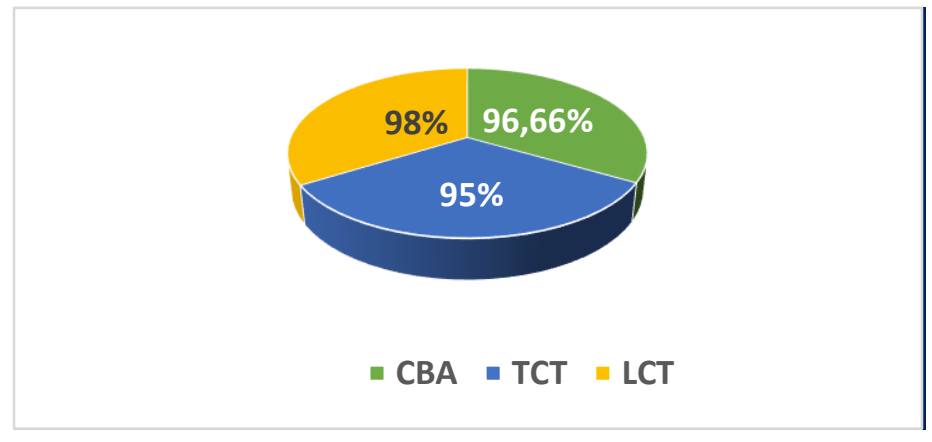

Figure 1. Teachers' Knowledge Extent about Teaching Approaches

Since the Algerian educational curriculums adopt the Competency-Based Approach, teachers have a clear theoretical idea about it. In their responses to the question related to the CBA definition, the respondents' responses revolved around the process of helping learners to develop their skills and competencies rather than filling their minds with foundational knowledge. As for the TCA and LCT approaches, all the respondents provided suitable definitions. They defined TCA as a traditional approach if it is overused. Some of their responses highlighted the predominance of the teacher in the classroom and the roles he plays: all day long lecturer, the sole information provider, assessor and evaluator, and curriculum transmitter. On the other hand, they defined LCT as an approach that shifts learners' roles from passive knowledge receivers to active participants responsible for their learning. In such a classroom environment, the teacher becomes a guide, facilitator, and prompter.

\subsection{Teachers' Teaching Methodology and Practice}

In this section, the researcher focused on the teaching approaches, strategies, and classroom materials. Concerning the first question of this section, which investigates the teaching approach teachers adopt most of the time in class, most respondents (63\%) stated that they use the LCT approach. However, the analysis of the subsequent questions contradicts this answer and shows that teachers use the TCA most of the time. However, those (37\%) who said they prefer using the 
TCA quoted that it is less time-consuming, enabling them to finish the program on time. They also added that it fits the slow learners and helps teachers control their classes effectively.

Concerning the second question related to teachers' frequent position in the classroom, most respondents $(67 \%)$ said they always stand up near the blackboard facing students. Such a position implies that the teacher plays the role of the sage on the stage who owns knowledge and transmits it to students through the perpetual chalk and talk method. However, the rest of the respondents (33\%) preferred taking different classroom positions during the lesson.

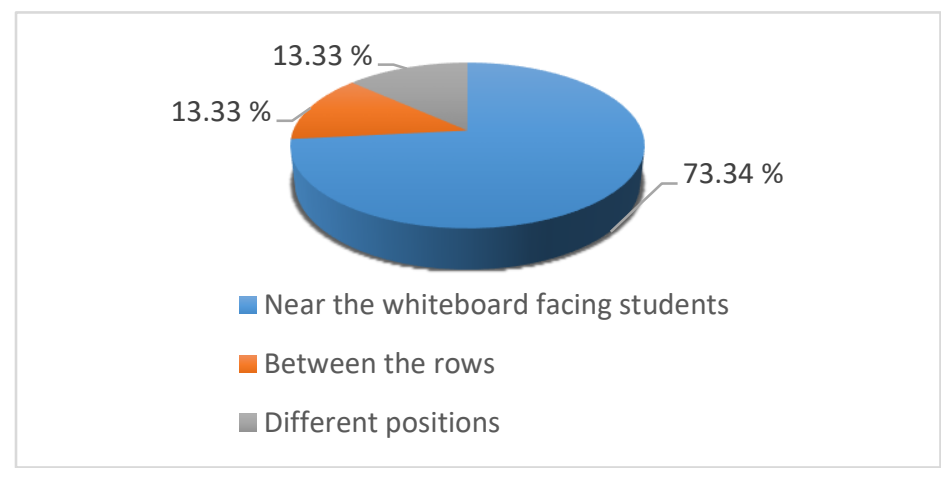

Figure 2. Teachers' Position in the Classroom

To answer the third question about who the primary knowledge supplier and evaluator is in the classroom, the majority (70\%) said that the teacher is the sole knowledge provider; some of them (20\%) gave that role to both the teacher and students, and few of them (10\%) gave it to students.

The fourth, fifth, and sixth questions investigate the use of active and interactive strategies like ICTs, pair and group work, games, puzzles, and role-play in the classroom. The respondents' answers stipulated that teachers rarely use those materials and techniques because of classroom crowdedness and the engendered noise.

In the seventh question, which focuses on students' motivation extent to learn English, their answers varied between slightly and very motivated. According to them, the literary streams are less motivated than the scientific ones. They stated that such lack of interest is mainly due to the unsuitable streaming of students. However, none of their responses referred to the teacher's responsibility in students' motivation enhancement. The analysis of the eighth question will support this hypothesis.

When asked whether teachers encourage competitiveness among students in the eighth question, all (100\%) answered positively. The following table gives details about how the respondents urged students to be competitive. 
Table 2. Teachers' Ways of Encouraging Competitiveness

\begin{tabular}{|l|c|}
\hline \multicolumn{1}{|c|}{ Competitiveness Encouragement Ways } & Teachers' Choices \\
\hline I give students quizzes and tests. & $\mathbf{5 3 ~ \%}$ \\
\hline I give good/extra marks to those who do well. & $\mathbf{9 0} \%$ \\
\hline I give rewards to those who do well. & $\mathbf{3 7} \%$ \\
\hline I encourage and praise those who do well. & $\mathbf{8 6} \%$ \\
\hline I give remarks to those who do not do well. & $\mathbf{3 0} \%$ \\
\hline
\end{tabular}

Once again, teachers' responses to this question show that the traditional teacher-centered paradigm influences their methodology. Instead of encouraging collaboration and cooperation, they prefer motivating students extrinsically through grades, rewards, and teacher-ignited competitiveness that produce short-term effects on students. In this case, the risk of expecting positive responses from students without rewards could be higher. Therefore, teachers should foster students' intrinsic motivation by creating a suitable learning environment that encourages them to develop their intrinsic motivation. Such an environment should be based on collaboration, students' interests and needs, relevant positive feedback, and problem-solving strategies to ignite curiosity and challenges.

The ninth question investigates teachers' utmost aim behind teaching. Most of the respondents (97\%) chose the proposed aims; whereas, a few of them $(03 \%)$ gave their aims:

- Help students learn and use the language communicatively in real-life contexts;

- Ensure life-long learning for students;

- Prepare students for the $21^{\text {st }}$ century.

Table 3. Teachers' Utmost Aim Behind Teaching

\begin{tabular}{|l|c|}
\hline \multicolumn{1}{|c|}{ Utmost Aims } & Teachers' Choices \\
\hline Help students pass the BAC exam. & $\mathbf{5 4 \%}$ \\
\hline Help students learn the program content. & $\mathbf{3 3 \%}$ \\
\hline Help students get good grades in the school exams. & $\mathbf{1 0} \%$ \\
\hline Other. & $\mathbf{0 3 \%}$ \\
\hline
\end{tabular}

These results highlight the importance teachers give to the BAC exam results. This assumption is due to teachers' pressure from parents and school authorities whose utmost aim is to have the highest numerical results in the BAC exam - an exam that is mainly based on content. Whether or not those students have built any life-long skills and competencies is nobody's concern. In this context, the teacher has no other choice than to provide students with the necessary exam hints and teaching them the required content to help them pass the BAC exam. That is why teachers teach the program content rather than help students learn and develop skills. Therefore, since the teacher is the expert and sole knowledge provider, he must adopt the teacher-centered approach to save time and finish the program on the recommended time. Concerning the first and third-year English programs, time shortage is also a constraint that forces teachers to work hard to finish them on time. The following table confirms the hypothesis about time constraints due to the length of the English programs. 
Table 4. Obstacles Hindering the English Programmes Completion

\begin{tabular}{|l|c|}
\hline \multicolumn{1}{|c|}{ Obstacles } & Teachers' Choices \\
\hline The lengthy programs. & $\mathbf{7 0 \%}$ \\
\hline Students' learning difficulties (slow learners). & $\mathbf{5 0 \%}$ \\
\hline A large amount of content in the coursebook. & $\mathbf{2 7} \%$ \\
\hline Class management difficulties. & $\mathbf{0 7 \%}$ \\
\hline
\end{tabular}

Concerning the tenth question about the obstacles that hinder the completion of the English programs, the respondents' answers (70\%) focused mostly on the length of the programs, especially the first and third-year ones. Half of the respondents (50\%) considered students' learning difficulties as an obstacle that hinders the completion of the programs. The rest of the answers revolved around the lengthy textbook content and the difficulties some teachers have to control their classes.

\section{Conclusion}

The Algerian English secondary-school programs are competency-based, and thus they recommend the use of active, cooperative, project-based, and problem-based methodology. However, in the field, teacher-centredness is still prevailing in classrooms. To investigate the causes of that prevalence, the researcher relied on both a questionnaire directed to English secondary school teachers and her experience as a teacher. The teachers' questionnaire responses confirmed the present study hypothesis, which stipulates that teachers know the effectiveness of the various teaching approaches. However, they keep adopt the teacher-centred method because they encounter many constraints during their practice. The questionnaire results showed that classrooms crowdedness hinders the use of the learner-directed active learning strategies because of the noise and problems of discipline they engender in the classroom. The results also revealed that the traditional physical classroom environment (aligned chairs and tables facing the blackboard) and the teacher's position (near the blackboard facing students) foster teacher centredness and lecturing. The respondents also referred to the content-based baccalaureate exam as a stimulant to the teacher-centred approach adoption since it urges them to teach the lengthy secondary-school English programs contents and finish them at the recommended time before the end of each year. Although the present study highlights one of the classroom practices that hinder the adoption of modern teaching approaches that develop students' 21 st-century skills, a question remains open for further research. How could we remedy teacher-centredness prevalence in Algerian secondary schools and produce a change in the current teaching paradigm?

\section{About the author:}

Meriem Baghoussi holds a Ph.D. in Didactics and Applied linguistics from Abdelhamid Ibn Badis University, Mostaganem, Algeria. She has been teaching English in secondary school for seven years. Her research interests center around EFL teaching and Psychopedagogy. https://orcid.org/0000-0001-5694-3364

\section{References}

Ackerman, C. E. (2020). Positive Reinforcement in Psychology. Retrieved on January 29 ${ }^{\text {th }}, 2021$ from: https://positivepsychology.com/positive-reinforcement-psychology/, (para. 2). 
Attard A., Di Iorio E., Geven K. \& Santa R. (2010). Student-Centred Learning-Toolkit for students, staff and higher education institutions. Education International, The European Students' Union, 1-73.

Ballard, K. D. (1987). The Limitations of Behavioural Approaches to Teaching: Some Implications for Special Education, The Exceptional Child, 34(3), 197-212.

Brophy, J. (1999). Perspectives of classroom management: Yesterday, today and tomorrow. In H. Freiberg (Ed.), Beyond behaviorism: changing the classroom management paradigm, 43-56. Boston: Allyn and Bacon.

Dollard, N., Christensen, L., Colucci, K. \& Epanchin, B., (1996). Constructive Classroom Management. Focus on Exceptional Children, 29(2), 1-12.

Dupin-Bryant, P. A. (2004). Teaching Styles of Interactive Television Instructors: A Descriptive Study. The American Journal of Distance Education, 18(1), 39-50.

Emaliana, I. (2017). Teacher-centered or Student-centered Learning Approach to Promote Learning? Jurnal Sosial Humaniora, 10(2), 59-70.

Kitiashvili, A. (2020). Shifting from a Teacher-Centred to a Student-Centred Approach in the General Education of Georgia: Attitudes and Classroom Practices of Teachers. International Journal of Innovation and Research in Educational Sciences, 7(6), 552-564.

Mascolo, M. (2009). Beyond Student-Centered and Teacher-Centered Pedagogy: Teaching and Learning as Guided Participation. Pedagogy and the Human Sciences, 1, 3-27.

MNE (2006). Program of English as a Second Foreign Language, Third Year Secondary School. Ministry of National Education, Algeria, Algiers, 3-23.

Muganga, L. \& Ssenkusu, P. (2019). Teacher-Centered vs. Student-Centered. Cultural and Pedagogical Inquiry. 11. 16-40. 10.18733/cpi29481.

Otukile-Mongwaketse, M. (2018). Teacher Centered Dominated Approaches: Their Implications for Today's Inclusive Classrooms. International Journal of Psychology and Behavioral Sciences, 10, 11-21.

Pavlov, I. P. (1927). Conditioned Reflexes: An Investigation of the Physiological Activity of the Cerebral Cortex. Translated and edited by Anrep, GV, 1927. Retrieved on January $27^{\text {th }}$, 2021 from: http://psychclassics.yorku.ca/Pavlov/lecture6.htm

Schug, M. C. (2013). Teacher-Centered Instruction: The Rodney Dangerfield of Social Studies. In Leming, J. et al. (2003). Where Did Social Studies Go Wrong?, p.94. Thomas B. Fordham Foundation, Washington, DC.

Skinner, B. F. (1938). The Behavior of Organisms: An Experimental Analysis. New York: Appleton-Century.

Speaks, S. (2019). Watson, Pavlov, Thorndike, Skinner and the Development of Behaviorism. Retrieved on January $29^{\text {th }}, 2021$ from: https://owlcation.com/social-sciences/CognitiveDevelopment-in-Children-from-Watson-to-Kohlberg.

Thorndike, E. L. (1911). Animal intelligence: Experimental studies. New York: The Macmillan Company, 244-272.

Toh, K.A. (1994). Teacher-Centred Teaching Is Alive and Well. Teaching and Learning, 15(1), 12-17.

Watson, J. B. (1924). Behaviorism. New York: People's Institute Publishing Company. 